\title{
Exacerbations of chronic obstructive pulmonary disease - A patients' perspective
}

\author{
Rachel Adams ${ }^{a}$, Niels Chavannes ${ }^{b}$, Kevin Jones ${ }^{a, *}$, \\ Marianne Stubbe Østergaard ${ }^{c}$, David Price ${ }^{d}$
}

\author{
a School of Population and Health Sciences, University of Newcastle upon Tyne, \\ Newcastle upon Tyne NE1 7RU, UK \\ b Department of General Practice, Maastricht University, The Netherlands \\ c Department of General Practice, University of Copenhagen, Oster Farimagsgade 5-Q, Denmark \\ d Department of General Practice and Primary Care, University of Aberdeen, Aberdeen, Scotland, UK
}

Received 19 July 2005; accepted 17 January 2006

\section{KEYWORDS}

COPD exacerbation;

Qualitative;

Primary rare;

Internctional

Patients' perspective

\section{Summary}

Background: ax actrobtons are now an irportint Clinical variable for research into,

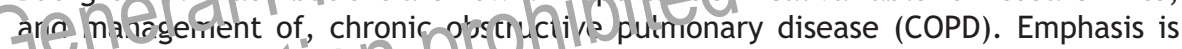
asually on reduction: (n the incidence of exacerbations and their impact on quality of lifer or sut. isesearch to be useful and comparable there needs to be a clearly Eefied understanding of what is meant by the term 'exacerbation'. The aim of this study was to explore the notion of COPD exacerbations from the viewpoint of patients who had recently suffered an exacerbation.

Methods: Using principles from grounded theory we conducted semi-structured, in-depth interviews with 23 volunteers from Denmark, the Netherlands and the UK who were identified as having had a COPD exacerbation. Interviews were recorded locally and translated into English for analysis. Notable themes were identified for each informant and their occurrences compared.

Results: Patients' reasons for consulting fell into four categories: 'frightening change'; 'change in sputum colour'; 'gradual deterioration'; and 'opportunistic diagnosis'. Most patients consulted frequently about their COPD, but did not afford their exacerbations the same degree of prominence as healthcare professionals (HCPs).

Conclusions: These data provide a new way of thinking about COPD exacerbations, offering a greater understanding and classification of the reasons underlying the decision of COPD patients to consult with HCPs. They suggest that the patient perspective of exacerbations is more complex than previously thought. These findings could be applied to clinical practice and research, facilitating focussed decisions on COPD management.

(c) 2006 General Practice Airways Group. Published by Elsevier Ltd. All rights reserved.

\footnotetext{
* Corresponding author.
}

E-mail address: K.P.Jones@ncl.ac.uk (K. Jones). 


\section{Introduction}

Research into chronic obstructive pulmonary disease (COPD) and its management has tended traditionally to use lung function as the main outcome variable. More recently, health status and exacerbations have become more important variables [1,2], the focus of the latter being on reducing their frequency, their cost to health care providers and their impact on the individual [3]. These variables - health status and exacerbations - are inextricably linked since it has been shown that the incidence of frequent exacerbations is associated with reduction in quality of life, increased symptoms, reduction in activity, and reports of COPD being the highest factor impacting on patients' daily lives [2]. And yet, despite these effects, there is evidence that patients under-report exacerbations [2]. There is therefore a need to understand better how patients with COPD exacerbations make decisions to consult healthcare professionals (HCPs). Furthermore, there is a need to understand better what patients perceive as an 'exacerbation.'

Studies vary in their definitions of COPD 'exacerbations' [4-15], thus making evaluation and comparison difficult, a problem identified in the GOLD international guidelines for t'ie management of COPD. Indeed the ayrics: of the GOLD guidelines uselthe eiricexacerbation, without inclean defirition [16]. There is turs a need for a consensus definition, which we believe must include a patients perspective [17]. Furthermore, since exacerbations are essentially a subjective experience, we believe that the link between 'exacerbations' (however defined) as perceived by clinicians, and the quality of life experienced by patients with COPD, must be demonstrated from the patients' perspective. Unless a strong link between these can be demonstrated, changes in numbers of 'exacerbations' are likely to continue to be problematic [2].

Our research aim, therefore, was to explore the notion of 'exacerbations' from the perspectives of patients with COPD across three countries. In so doing we explored aspects such as: how decisions were made to consult; symptoms; how symptoms differed from those on 'bad days'; treatment; and impact on daily activities. Since our aim was exploratory, not to test an hypothesis but rather to generate new data, a qualitative approach was chosen. We set out to obtain a greater understanding of patients' perspectives on COPD and its exacerbations in order to inform a consensus definition.

\section{Methods}

The study was conducted in the city of Copenhagen in Denmark, the village of Bocholtz in the Netherlands and the urban district of Gateshead in the UK, which in part controlled for issues related to individual health care systems. The three sites were chosen because of the researchers' previous experience of respiratory medicine in primary care and their units' experience of qualitative research.

A convenience sample was obtained of patients with a diagnosis of COPD in their primary care records who had presented for unscheduled treatment for their COPD within the last six weeks. Those with confounding co-morbidity were not excluded, thus reflecting more accurately primary care practice. Sampling until saturation of themes had been attained (continuing data collection until no new themes emerge) would have been preferable but time and financial constraints prevented this.

Ethical approval was obtained locally in each of the countries. Volunteers received written and verbal information about the study ina a vance, with written consent obtained or the time of interview.

Volunter: viere rectuited from local primary are Centres (PCCS) identified by the clinical

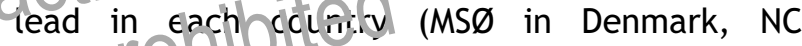
in in: (Aetheriands and $\mathrm{KJ}$ in the UK). In the UK, eligible patients from five PCCs were identified retrospectively from electronic records, from consultations, or by the respiratory nurse at the local hospital, and were invited to participate. In Denmark, two PCCs invited patients to participate who were known to have COPD. In the Netherlands, two PCCs invited eligible patients to participate when seen during the recruitment period. Resources (time and translation costs) allowed for the recruitment of 24 patients across the three countries.

The volunteers participated in semi-structured, in-depth interviews conducted and recorded by local researchers. Limited quantitative data, including spirometry recordings to confirm severity and diagnosis, were also gathered. Participants were encouraged to discuss exacerbations in the context of their daily lives. Topic lists and question stems were given to the interviewers to guide them; for example, "Their recent exacerbation: what were the symptoms and how did they begin?"' See Figure 1 for further examples.

Recordings were transcribed locally and translated into English by researchers with a special interest in linguistics, conversation analysis and cultural context, to enable them to be 


\begin{tabular}{|c|}
\hline Their recent exacerbation: \\
\hline When this was? \\
\hline What were the symptoms \& how did they begin? \\
\hline $\begin{array}{l}\text { What did they do to alleviate them \& how effective were these } \\
\text { measures? }\end{array}$ \\
\hline Why did they decide to seek medical treatment? \\
\hline $\begin{array}{l}\text { Did they go to anyone else for advice first? If so, how did they contact } \\
\text { them? }\end{array}$ \\
\hline How did they call for help? \\
\hline What did the medical team do? \\
\hline How effective was this; how long did they have to wait for this effect? \\
\hline How long was it before they felt back to normal/recovered? \\
\hline $\begin{array}{l}\text { During this time did they need extra help from others? If so from whom } \\
\& \text { what did they do? }\end{array}$ \\
\hline $\begin{array}{l}\text { If they haven't returned to their previous level of health how is their new } \\
\text { state different to the former? }\end{array}$ \\
\hline What do they think triggered this event? \\
\hline How do such events make them feel (their attitude toward them)? \\
\hline $\begin{array}{l}\text { How many other attacks like these have you had over the last } 12 \\
\text { months? }\end{array}$ \\
\hline What, if anything, was different about any of these? \\
\hline Do their symptoms vary in-between these attacks? \\
\hline If yes, how are they different? And with what frequency? \\
\hline $\begin{array}{l}\text { Why do these attacks not require medica } \\
\text { What do they think da isc such events? }\end{array}$ \\
\hline How are they alleviated? \\
\hline Do they require help and advice from others during this time? \\
\hline How does their breathing affect them on a day-to-day basis? \\
\hline What things can/can't they do? \\
\hline What things do they need help with \& who provides this? \\
\hline $\begin{array}{l}\text { How does living with this disease make them feel/what's their } \\
\text { attitude towards it? }\end{array}$ \\
\hline $\begin{array}{l}\text { What do they think are the most important things that we* should be } \\
\text { doing for them? }\end{array}$ \\
\hline $\begin{array}{l}\text { What changes would they like to see in their disease and the way it } \\
\text { affects their lives? }\end{array}$ \\
\hline $\begin{array}{l}\text { What things do they think would make life with breathing difficulties } \\
\text { easier? }\end{array}$ \\
\hline Is there anything else they'd like to add? \\
\hline $\begin{array}{l}\text { *The ambiguous term 'we' is used here in the hope that the patients interpret } \\
\text { it as meaning not just medical issues but other non-medical issues as well. }\end{array}$ \\
\hline
\end{tabular}

Figure 1 Question stems. analysed as a whole by the full-time researcher in the UK (RA). Analysis included probing into the tacit knowledge (knowledge held in common with others in one's social group, but which is not easily explained) within the transcripts. These data were added as notes/memos on the transcripts. Checks over meanings were made with the interview teams and translators as necessary. Data analysis sought to identify patterns of themes between patients [18]. Analytical categories were identified by reading and re-reading the transcripts and writing down ideas regarding interpretation. NVivo [19] was used to record the evidence from within the transcripts for those categories identified. From these data, summaries of each transcript were made and the categories present listed; these were checked by the interview teams (who spoke English) and the translators. The summaries were compared with each other in order to identify common patterns in the presentation of the analytical categories across the three data sets. Categories not common to each data set were discarded. The emergent themes from this process were discussed with the clinical leads in each country. Thus, each stage invelved (iiscussion. It was through the latterSdiscission that our final findings en mirged. a y

\section{Resilit:}

From a sample of 28 patients, 23 interviews were obtained (11 in the UK, and six each in Denmark \& the Netherlands). Reasons for not recruiting volunteers included ineligibility and patients feeling too unwell to be interviewed. Recruiting staff advised that no-one whom they had invited to participate had declined. The participants comprised 16 men and seven women with ages ranging from 38 to 84 years (see Table 1). The median time between consultation and interview was $3 \frac{1}{2}$ weeks. All but one of the patients were over 60 years of age; nine were in their sixties, nine in their seventies, and four in their eighties. Most of those in their sixties had severe COPD. Those in their eighties had severe or moderately severe COPD. HCPs, particularly those in primary care, treat patients of all COPD severities. Our sample comprises patients with a range of moderate to very severe COPD (GOLD II-IV). Their smoking histories varied from 8 to 150 pack years and their COPD severity was moderate or severe in every case assessed by spirometry. The median number of self-defined exacerbations in the preceding 12 months was three. 
Table 1 Demographic and clinical data

\begin{tabular}{|c|c|c|c|c|c|c|}
\hline ID & Sex & $\mathrm{Age}^{\mathrm{a}}$ & Alone & Pack Years & FEV1 \% predicted & Severity of COPD \\
\hline UK1 & M & 63 & $\mathrm{~N}$ & 40 & 18 & IV (Very Severe) \\
\hline UK2 & $\mathrm{F}$ & 77 & $Y^{*}$ & 63 & 36 & III (Severe) \\
\hline UK3 & $\mathrm{F}$ & 71 & $\mathrm{~N}$ & 76.5 & 15 & IV (Very Severe) \\
\hline UK4 & M & 38 & $\mathrm{~N}$ & 24 & 26 & IV (Very Severe) \\
\hline UK5 & M & 70 & $\mathrm{~N}$ & 52.5 & 28 & IV (Very Severe) \\
\hline UK6 & M & 69 & $\mathrm{~N}$ & 64 & 23 & IV (Very Severe) \\
\hline UK7 & M & 87 & $\mathrm{Y}$ & 72 & 72 & II (Moderate) \\
\hline UK8 & M & 65 & $Y$ & 150 & 14 & IV (Very Severe) \\
\hline UK9 & $\mathrm{F}$ & 75 & $Y$ & 42 & 32 & III (Severe) \\
\hline UK10 & $\mathrm{F}$ & 80 & $Y^{*}$ & 40 & 37 & III (Severe) \\
\hline UK11 & $\mathrm{F}$ & 69 & $Y^{*}$ & 34.5 & 57 & II (Moderate) \\
\hline DK1 & M & 77 & $\mathrm{~N}$ & 37.5 & 55 & II (Moderate) \\
\hline DK2 & $\mathrm{F}$ & 74 & $Y$ & 40 & 32 & III (Severe) \\
\hline DK3 & M & 67 & $\mathrm{Y}$ & 75 & 21 & IV (Very Severe) \\
\hline DK4 & M & 82 & $\mathrm{~N}$ & 22.5 & 41 & III (Severe) \\
\hline DK5 & $\mathrm{F}$ & 79 & $\mathrm{Y}$ & 44 & - & - \\
\hline DK6 & M & 62 & Y & 35 & 46 & III (Severe) \\
\hline ND1 & M & 62 & $\mathrm{~N}$ & 24 & 12 & IV (Very Severe) \\
\hline ND2 & M & 68 & $\mathrm{~N}$ & 52 & 26 & IV (Very Severe) \\
\hline ND3 & M & 64 & $\mathrm{~N}$ & 13 & 46 & III (Severe) \\
\hline ND4 & M & 84 & $\mathrm{~N}$ & 36 & 38 & III (Severe) \\
\hline ND5 & M & 76 & $\mathrm{~N}$ & 8 & 38 & $\because(S) V \in r E)$ \\
\hline ND6 & $M$ & 76 & $Y^{\Delta}$ & 36 & 22 & V (Very Severe) \\
\hline
\end{tabular}

M: Male; F: Female; N: No - did not live alone; Y: Yes - did live alc ne. *: Aive Identifier; ${ }^{\Delta}$ : Wife lives in a nursing home; -: Missing $\mathrm{Da}$ 'a.

a Age at time of interview.

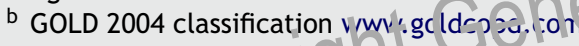

\section{Our Patients Perspective Exizervations}

Prominence of exacerbations in life with COPD

At the beginning of the interview patients were asked to describe what it is like to live with "breathing problems" [life with COPD]. The frequency and disruptive nature of needing to access HCPs was not presented as a key part of their narrative, despite the fact that most of our patients would have been classed as having 'frequent' exacerbations (see above). Instead, they focussed on the impact of COPD on their daily lives, often referring to the 'up and down' nature of their days. Reference to visits with an HCP tended to be in relation to the most recent one (in line with the interviewer's request) or a specific event of particular significance to the individual. As expected, they did not use the word 'exacerbation.' Examples of these are summarised below:

UK3 was invited to:

"... tell [us] in your own words what it's like living with your breathing problems..."
Reply: "a nightmare," "horrible". She talked about the nights, the history of her disease, her daily life, her previous job, pulmonary rehabilitation, cancelling holidays and her husband.

ND1 was asked:

"When you got problems with your airways, tell me what happened. What problems did you have and what was the reason for you to see the doctor? Tell me in your own words."

Reply: He talked about his sporting activities, the onset of his disease, his pigeons and his medication.

\section{DK5 was asked:}

To talk about "the last aggravation of her disease"

Reply: She talked about her new doctor, things which made her breathless, her daily life, her cleaner, her symptoms, her medications, lung function tests, the feeling of suffocation, her avoidance of those with colds, journeys out of the house, and the disease's onset. 


\section{Decisions to consult}

Most of the patients were, in fact, reluctant to consult, tending to do so only under particular circumstances (see section "A new perspective Classification of exacerbations"' below):

WUK1: "l'd to fight with [my husband] to come [to see the doctor]."

ND1: "I don't easily go to see a doctor."

DK5: "it has to be really bad for me to ... see the doctor"'

\section{Exacerbations as 'forgotten' events}

Some patients, when asked about their visit with an HCP, did not immediately remember the 'exacerbations' being referred to. Exacerbations did not seem that memorable, suggesting that they were not necessarily conceptualised as significant events:

I: "So you had to go and see the doctor recently about your chest, didn't you, last month?"'

UK10: "... when I came out of hospital [3 months ago] ..."'

I: "I was told that [it was 6 weeks ago]"

UK10: ". . to see the doctor, yes"

I: "DK3, the last serious aggravation of your lung disease, when was that?"

DK3: "I actually can't [remember] hecause..., it's actually been maky tears

[He hariactualy beer hospitalised 1 mont for his COFD. The interviener the this, so made reference to it in order to develop the discussion further.]

I: "what happened recently when you had problems with your airways?"

Reply: ND4 talked about the history of his COPD.

\section{Symptoms on bad days vs those at time of} consultation

When participants were asked what had been wrong with them when they had recently seen the HCP, their responses centred around the symptoms listed in Figure 2. However, as can be seen in the quotations below, patients with COPD often feel unwell - they have "good days and bad days." They used the same descriptors to describe those bad periods and those occasions when they sought help from an HCP.

UK2 "I'm all right one day and all around the next."

ND2 "It's up and down, sometimes a bit better and then it's a bit worse."

DK4 "... once we get to the afternoon I'll be feeling like an old rag..."

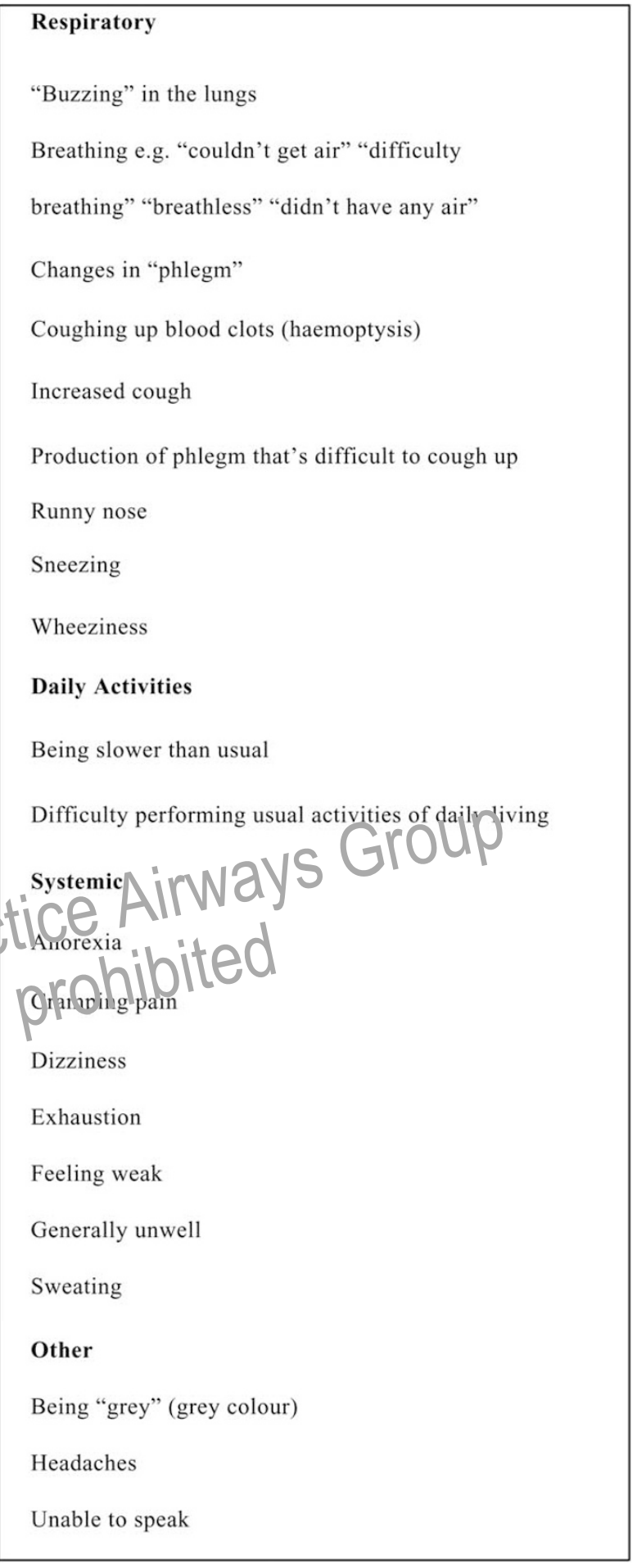

Figure 2 Symptoms associated with exacerbations.

\section{Attitude toward exacerbations}

Attitudes toward exacerbations were identified through direct questioning and incidental comments during the interview: 
ND4: " [when I have these relapses] I'm optimistic, I don't get [upset] that easily, I feel most miserable when l've done something that's beyond me."

DK3: "...one's used to not always feeling good."

UK5: "going to the doctor's for antibiotics doesn't bother us..."

\section{Research priorities}

The fact that exacerbations were not of high priority to our COPD patients is further reinforced by informants' responses to our queries about their research priorities and treatment goals:

UK8: "The breathlessness is the worst thing. .."

DK3: "...l'd like just to be able to walk from upstairs, going down without having to sit down a couple of times to catch my breath..."

ND5: "during activity the air just disappears, that's the worst.",

When asked "what things would make [their] life easier... if they had a wish list..." they did not express concern about their visits to HCPs. Instead, beyond getting "rid of their disease," the most prevalent goal was to reduce its day-to-d-iy limitations.

\section{A New Perspectivé t.Caclassification of Exacerbitions}

It was extremely difficult for our patients to explain how triggers for HCP consultation differed from 'bad days'. However, when the transcripts were summarised it became apparent that there were differences in the way our patients decided to consult. These reflected the different nature of the patients' exacerbations. Categories that we saw are listed below. Whilst not exclusive or exhaustive, they summarise the broad breadth of patient experience that we saw in our particular sample.

(1) Frightening change

In this scenario participants either called for the emergency services, arranged (during working hours) for a GP visit, or were able to see their GP the same day. The events themselves might be very different, the common factor was the fear induced.

(2) Change in sputum colour

In this scenario there was for some, but not all, an accompanying story of being unwell. The key point is that the discoloured sputum prompted an immediate decision to contact an HCP.
(3) Deterioration, reaching a point of crisis These patients described how they had become increasingly disabled and/or 'unwell' until a crisis point was met where they couldn't cope anymore. Crises included being newly unable to get upstairs to go to bed or the desperation of family members.

(4) Opportunistic diagnosis of exacerbation Here, treatment was not initiated by the patient, but by the HCP during a planned COPD check up/review or a visit for another health problem.

\section{Discussion}

This study explored patient perspectives of COPD exacerbations with the intention that they be used to contribute to a single, simple, consensus definition. We sought to understand the patient perspective and not to explore patient experiences of a predefined event. We therefore recruited patients on the basis of their need for unscheduled treatment for their COPD, since it is these events that we in primary care seek to treat and understand. Instead, we have forand hat there are a range of ways in wirch n tients experience a temperary crar ge from their baseline COPD imptons, that is, an exacerbation. Currently, there are rich auins or sub-categories for cracerbit cn scenarios. The findings of this study can be used to further our understanding of the experience of exacerbations, and to suggest a classification for them.

Content analysis of our results revealed symptoms akin to those in a textbook (see Figure 2). However, knowing that COPD is a disease characterised by 'good days' and 'bad days' we sought also to understand how 'bad days' differed from days requiring HCP intervention and what exactly prompted our patients to seek healthcare. By listening to and comparing these stories we were able to see that there were a range of events which led them to seek healthcare.

Concern has previously been expressed that patients sometimes fail to consult when they need to [2]. We believe that thinking about "categories" of exacerbations, as described here, adds a new and valuable level of understanding of the patients' perspective, and addresses, at least in part, discrepancies described in the number of exacerbations reported by patients in some studies $[2,20]$. Whilst our patients had relatively high numbers of annual exacerbations, they also reported reluctance to consult. Our patients were prompted by either a frightening experience, a recognisable change in their sputum, 
or a crisis resulting from a gradual deterioration. Whilst a range of symptoms - associated with COPD exacerbations by HCPs - may have been present, it seems that these did not necessarily trigger consultations in this cohort. One of the crucial factors prompting consultation appears to have been the anxiety and distress induced by their symptoms in either the individual or those around them. These findings, which have been reported previously [21-23], make the reluctance to consult even more puzzling. This reluctance may relate to their experience of the patient-doctor relationship. Previous research $[22,23]$ has described how some patients do not feel that their fear is understood and that they had been told that their general practitioners (GPs) could not do any more for them. This latter point was also found in our study, along with stories of unsatisfactory consultations. These factors may be amongst the significant points that need to be tackled if we are to improve the treatment of COPD exacerbations. We have to be more active in giving clear instructions to patients when to consult HCPs, since early treatment improves prognosis and can prevent hospitalization $[20,24]$.

This paper emphasises the need to remember that, as individuals vary, so do their disease experiences. Empowering patients so that ney have a greater role in the managemicit at their disease might thereforb steen thuppropriate way forward. Hovever, triall findings of the etficla $-y$ d standardised sel-managemert togrannes have shown mixed results $[20,25]$. The need to have one's COPD understood and to be offered personal treatment was found here, and previously by Cicutto et al. [23]. This reiterates the need for greater understanding of COPD, and also greater care in trial designs.

Research today is disseminated internationally and countries seek to learn from each other. However, there is often concern regarding applicability between countries. This study was set in three countries. The GPs who collaborated in its design felt that whilst some aspects in the process of their healthcare delivery systems differed, the three were largely comparable in their provision of primary care, access to primary care practitioners, and treatments. In the subsequent data analysis, no differences in patient perspectives of exacerbations were identified that appeared to be culturally specific.

The numbers for this study were necessarily small given the time required when using qualitative techniques for analysis. Whilst this limits the generalisability of our findings, it has enabled us to go beyond describing our patients' experiences, and to suggest the beginnings of an explanation. What is particularly interesting is that despite different interviewers, with different styles, the same themes were still identified. Exploring our findings in broader contexts would be particularly useful.

Patient perspectives of COPD exacerbations appear more complex than previously thought. Our findings provide a means of categorising exacerbations from the patients' perspective. These could be applied to clinical practice and research, thus facilitating focussed decisions on COPD management, including patient education and follow-up. Furthermore, they provide an opportunity to think afresh about the images we hold of 'exacerbations', providing a means of breaking down some of the stereotypes that might exist relating to COPD. Further exploration of our categories may help to evaluate the primary care management of this common and disabling condition in a new light.

\section{Conflict of interest statement}

There are no conflicts of interest to be declared.

\section{Acknowledgemeits}

Thus vrork was sponsored by an unrestricted educational gran Provided to the International Prinary Care Respiratory Group (IPCRG) from Boehringer-Ingelheim $\mathrm{GmbH}$ in Germany for peerapproved research in COPD, for which we are very grateful. Our thanks also go to all those others who have made this work possible - other members of the IPCRG, other researchers who have discussed various stages of the evolution of the project, practice-based nurse and doctor colleagues, and of course most importantly the patients without whose interest, involvement and cooperation we would have had nothing to report.

\section{References}

[1] Donaldson GC, Seemungal TAR, Bhowmik A, et al. Relationship between exacerbation frequency and lung function decline in chronic obstructive pulmonary disease. Thorax 2002; 57:847-52.

[2] Seemungal TAR, Donaldson GC, Paul EA, et al. Effect of exacerbation on quality of life in patients with chronic obstructive pulmonary disease. Am J Respir Crit Care Med 1998;157(5):1418-22.

[3] Molen van der T, Pieters W, Bellamy D, et al. Measuring the success of treatment for chronic obstructive pulmonary disease - patient, physician and healthcare payer perspectives. Respir Med 2002;96:S17-21.

[4] Anthonisen NR, Manfreda J, Warren CPW, et al. Antibiotic-Therapy in Exacerbations of Chronic Obstructive Pulmonary-Disease. Ann Intern Med 1987;106(2):196-204. 
[5] Guell R, Casan P, Belda J, et al. Long-term effects of outpatient rehabilitation of COPD: a randomised trial. Chest 2000;117:976-83.

[6] Casanova C, Celli B, Tost L, et al. Long-term controlled trial of nocturnal nasal, positive pressure ventilation in patients with severe COPD. Chest 2000;118:1582-90.

[7] Friedman M, Serby C, Menjoge S, et al. Pharmacoevaluation of a combination of ipratropium plus albuterol compared with ipratropium alone and albuterol alone in COPD. Chest 1999;115:635-41.

[8] Vincken W, van Noord J, Greefhorst A, et al. Improved health outcomes in patients with COPD during one year's treatment with tiotropium. Eur Respir J 2002;19:209-16.

[9] Casaburi R, Briggs D, Donohue J, et al. The spirometric efficacy of once-daily dosing with tiotropium in stable COPD. Chest 2000;118:1294-302.

[10] Boom van den G, Rutten van Molken M, Molema J, et al. The cost-effectiveness of early treatment with fluticasone propionate $250 \mathrm{mcg}$ twice a day in subjects with obstructive airway disease. Results of the DIMCA program. Am J Respir Crit Care Med 2001;164:2057-66.

[11] Grunsven van P, van Schayck C, Derenne J, et al. Long term effects of inhaled corticosteroids in chronic obstructive pulmonary disease: a meta-analysis. Thorax 1999;54:7-14.

[12] ZuWallack R, Mahler D, Reilly D, et al. Salmeterol plus theophylline combination therapy in the treatment of COPD. Chest 2001;119:1661-70.

[13] Watson P, Town G, Holbrook N, et al. Evaluation of a self-management plan for chronic obstructive pulmonary disease. Eur Respir J 1997;10:1267-71.

[14] Suzuki T, Yanai M, Yamaya $M$, et al. Erythromycin and common cold in COPD. Chest 2001;120:730-3.

[15] Paggiaro P, Dahle R, Bakran I, et al. Multicentre randomised placebo-controlled trial of inhaled fluticasone prenionat:e in patients with chronic obstruc'ive pu'monar d:sease. Lancet 1998;351:773-80
[16] National Institutes of Health: National Heart L, and Blood Institute. Global initiative for chronic obstructive lung disease global strategy for the diagnosis, management, and prevention of chronic obstructive pulmonary disease: Updated 2003: http://www.goldcopd.com/revised.pdf, 8/28/03.

[17] Price D, van der Molen T. The Aberdeen primary care COPD research needs statement March 2001. Prim Care Respir J 2001;10:47-50.

[18] Miles $M$, Huberman A. Qualitative data analysis: A sourcebook of new methods. Beverly Hills, CA: Sage Publications Ltd; 1984.

[19] Richards L. Using NVivo in Qualitative Research. London: Sage Publications; 1999.

[20] Bourbeau J, Julien M, Maltais F, et al. Reduction of hospital utilization in patients with chronic obstructive pulmonary disease - A disease-specific self-management intervention. Arch Intern Med 2003;163(5):585-91.

[21] Bailey PH, Tilley S. Storytelling and the interpretation of meaning in qualitative research. J Adv Nurs 2002;38(6):574-83.

[22] Oliver SM. Living with failing lungs: the doctor-patient relationship. Fam Pract 2001;18(4):430-9.

[23] Cicutto L, Brooks D, Henderson K. Self-care issues from the perspective of individuals with Chronic Obstructive Pulmonary Disease. Patient Educ and Counselling 2004;55:168-76.

[24] Wood-Baker R, Walters EH, Gibson P. Oral corticosteroids for acute exacerbations of chronic obstructive pulmonary disease. The Cochrane Datioase $\mathrm{S} / \mathrm{t}$ Rev 2001:2 (CD001288. DOI: 10.1002/14.551858).

[25] Monninkho E Van (16: Valk $P$, van der Palen J, van $C^{\prime} H=$ w , arden $C$, Zielhuis $G$. Effects of a comprehensive self-management pos ramme in patients with chronic onst u i ike putmonary disease. Eur Respir J (0). $; 22.815-20$.

Available online at www.sciencedirect.com

science@Direct.

Available online at http://www.thepcrj.com 